\title{
Effect of exogenously applied 20-hydroxyecdysone on the efficiency of primary photosynthetic processes substantially differs across plant species
}

\author{
D. HOLÁ+, K. FRIMLOVÁ, M. KOČOVÁ, H. MARKOVÁ, O. ROTHOVÁ, and L. TƯMOVÁ \\ Department of Genetics and Microbiology, Faculty of Science, Charles University, Viničná 5, 12843 Prague, \\ Czech Republic
}

\begin{abstract}
The effects of 20-hydroxyecdysone on the primary photosynthetic processes (PPP) were examined across twelve plant species using the OJIP chlorophyll fluorescence analysis. Our experiments brought evidence that the ecdysteroids can function not only as protective compounds in plants but participate also in the regulation of photosynthesis. Exogenously applied 20-hydroxyecdysone positively affected the PPP particularly in French bean and canola. Contrary to this, the PPP were negatively influenced by 20-hydroxyecdysone in pea, sunflower, and wheat. The performace of the oxygenevolving complex, the excitonic connectivity among PSII units, the electron transport between PSII and PSI, the size of the pool of the end electron acceptors, and the absorption and trapping of the excitation energy in the light-harvesting antennae were differently affected in individual plant species. Additionally, the older and younger leaves did not respond to 20-hydroxyecdysone in the same way and this was also a species-specific phenomenon.
\end{abstract}

Additional key words: electron transport chain; interspecific variability; OJIP analysis.

\section{Introduction}

Plants contain a wide variety of sterols that are important structural components of cell membrane and impact its fluidity, signalling processes and the activity of some membrane proteins. Sterols also fulfill other biological roles, such as regulation of plant growth, development, stress response, etc. (Moreau et al. 2002, 2018; Valitova et al. 2016). Brassinosteroids (BRs) are probably the best studied plant sterol derivatives with the most extensive distribution among plant species. However, many plants also synthesize another type of oxysterols called ecdysteroids (ECs). These compounds are frequently present in high amounts in various plant organs (particularly young leaves and reproductive organs) and are generally regarded as antifeedants/endocrine disruptors for phytophagous insects or nematodes, or as allelochemicals (Dinan et al. 2001, Tarkowská and Strnad 2016, Thiem et al. 2017).

In addition to this protective role, some evidence that ECs can fulfill other physiological/regulatory functions in plants (or other photosynthetic organisms) has also been presented. One set of studies was made with photosynthetic alga Chlorella vulgaris and the results showed that various ECs stimulate growth and several metabolic activities in this organism (Bajguz and Koronka 2001, Bajguz and Dinan 2004) and protect it against lead stress (Bajguz and Godlewska-Zylkiewicz 2004).
Stimulation of shoot elongation during early stages of wheat or tomato development by 20-hydroxyecdysone (2 $\beta, 3 \beta, 14 \alpha, 20 \beta, 22,25$-hexahydroxy-7-cholesten-6-one; $20 \mathrm{HE}$ ), which is the most common representative of ECs in higher plants, was observed by Golovatskaya (2004) and Bakrim et al. (2007). Haitov et al. (2013) and Li et al. (2018) showed that 20HE alleviates the negative effects of salinity in cotton. Similarly, Lamhamdi et al. (2016) demonstrated that this compound can protect wheat plants against lead stress. Thussagunpanit et al. (2018) reported that this particular ecdysteroid did not significantly affect the elongation of Arabidopsis hypocotyl, but two of its synthetic derivatives increased hypocotyl length in this plant species. The same group of authors also demonstrated the protective role of these compounds against drought or heat stress in chili pepper and rice (Thussagunpanit et al. 2015a,b; Sonjaroon et al. 2016, 2018; Khamsuk et al. 2018).

Thus far, two processes have been suggested as the main prospective targets of the $20 \mathrm{HE}$ action in plant cells in connection with the possible role of ECs in the regulation of higher plant growth, development, and stress response. One of them is the activity of antioxidative and osmoprotective systems (Lamhamdi et al. 2016, Li et al. 2018), the other one is photosynthesis (Uhlík et al. 2008). Our previous experiments showed that the exogenous application of $20 \mathrm{HE}$ can indeed affect photosynthesis,

Received 28 February 2020, accepted 9 June 2020.

${ }^{+}$Corresponding author; phone: +420 221951 200, e-mail: danahola@natur.cuni.cz

Abbreviations: 20HE - 20-hydroxyecdysone; BRs - brassinosteroids; EC - ecdysteroids; F - fluorescence; OEC - oxygen-evolving complex; PETC - photosynthetic electron transport chain; $\mathrm{W}$ - relative variable fluorescence.

Acknowledgements: This work was financially supported by the Charles University Grant Agency (grant nr. 200516) and the Charles University research funding projects (SVV 260426 and SVV 260568). 
particularly some parameters associated with the efficiency of the photosynthetic electron transport chain (PETC) and/or the energy capture by photosynthetic pigments (Holá et al. 2013, Rothová et al. 2014). Interestingly, when we analyzed the response of the photosynthetic apparatus to $20 \mathrm{HE}$ in spinach (Spinacia oleracea L.), maize (Zea mays L.), and New Zealand spinach (Tetragonia tetragonioides L.) we found that these species differed: a slight positive effect was observed in maize and New Zealand spinach whereas a rather pronounced negative effect was found for common spinach. Additionally, PSI and PSII were affected differently in these species (Holá et al. 2013, Rothová et al. 2014). In order to further examine this phenomenon, we decided to perform a more detailed examination of the response of various parts of the PETC to exogenously applied 20HE, with particular regard to the potential interspecific variability.

\section{Materials and methods}

Plant material, cultivation conditions and experimental design: Twelve plant species were analyzed: pea (Pisum sativum L. cv. Oskar), French bean (Phaseolus vulgaris L. cv. Maxidor), faba bean (Vicia faba L. cv. Merkur), soybean [Glycine $\max$ (L.) Merril cv. Brunensis], canola (Brassica napus L. cv. Benefit), radish (Raphanus sativus L. cv. Kvinta), tomato (Solanum lycopersicum L. cv. Pavlína), cucumber (Cucumis sativus L. cv. Ivonna), sunflower (Helianthus annuus L. cv. Autumn Beauty), wheat (Triticum aestivum L. cv. Astrid), barley (Hordeum vulgare L. cv. Francin), and sorghum (Sorghum bicolor Moench. cv. Ruzrok). Seeds were sown into pots $(12 \times$ $12 \mathrm{~cm}, 1$ plant per pot; in case of wheat and barley 5 plants per pot) filled with Garden Compost (Agro CS, Czech Republic), placed in a greenhouse (Faculty of Science, Charles University, Prague, Czech Republic, $54^{\circ} 04^{\prime} \mathrm{N}, 14^{\circ} 25^{\prime} \mathrm{E}$, mean air temperature of $24 / 16^{\circ} \mathrm{C}$, mean relative air humidity of $70 / 86 \%$ day/night, natural irradiation (approximately $600 \mu \mathrm{mol}$ (photon) $\mathrm{m}^{-2} \mathrm{~s}^{-1}$ at noon), mean day length at the time of treatment $10 \mathrm{~h}$ ) and sufficiently watered during the whole cultivation period. After 3 (pea, faba bean), 4 (wheat, barley, sorghum), 5 (French bean, tomato, sunflower), 6 (soybean, canola, radish) or 7 (cucumber) weeks from the date of sowing, all plants displayed two fully developed true leaves and the size of the third, not yet fully developed leaf enabled photosynthetic measurements. At this time, the plants of each species were divided into two groups: plants treated with $20 \mathrm{HE}$ and plants treated with distilled water (control).

Treatment of plants with 20HE: The $10^{-4}$ M $20 \mathrm{HE}$ aqueous solution was prepared by dissolving 20HE (SigmaAldrich, USA) in distilled water. The $10^{-4} \mathrm{M}$ concentration was selected as the most effective one (we examined ten other concentrations down to $10^{-14} \mathrm{M}$ but their use did not result in any significant effect on the efficiency of primary photosynthetic processes). Tween ${ }^{\circledR} 20$ (Sigma-Aldrich, USA) was added as surfactant $(1: 1,000 ; \mathrm{v}: \mathrm{v})$ to the $20 \mathrm{HE}$ solution as well as to the control (distilled water). The first (older) and the third (younger) leaves were repeatedly (three times during a 5-min interval) sprayed over their whole area using a hand-held sprayer; in addition to this, the whole plants were also sprayed from their top. The amount of solution used per one plant was $5-10 \mathrm{~cm}^{3}$ (depending on the plant species and the dimensions of the respective leaves). In all cases, the leaves were completely covered by the respective treatment solution from both abaxial and adaxial side. All plants were always treated at 8:00 h Central European Time, approx. $1 \mathrm{~h}$ after sunrise.

Chlorophyll (Chl) fluorescence was measured on the adaxial surface of the first and the third leaves after 1 , $24,48,72$, and $168 \mathrm{~h}$ after the treatment of plants with $20 \mathrm{HE}$ or distilled water. After the treatment (40 min), the plants were moved into a completely dark room for $20 \mathrm{~min}$ dark adaptation, after which the first OJIP measurements were made (which corresponded to the time point $1 \mathrm{~h}$ after the treatment). The subsequent measurements were performed during the following days always at 8:00 h, again with 20 -min period of dark adaptation prior to the respective time point. The analysis of the polyphasic rise of Chl fluorescence transient (OJIP) based on the theory of energy flow in the PETC (Strasser et al. 2004) was utilized for the determination of the efficiency of the primary photosynthetic processes and various components of the PETC. All fluorescence transients were recorded using the portable fluorometer FluorPen 100max (Photon Systems Instruments, Czech Republic) with a time scan from $10 \mu \mathrm{s}$ to $2 \mathrm{~ms}$, the intensity of the saturating pulse (blue light, $455 \mathrm{~nm}$ ) was $3,000 \mu \mathrm{mol}$ (photon) $\mathrm{m}^{-2} \mathrm{~s}^{-1}$. The values of fluorescence recorded at $40 \mu \mathrm{s}\left(\mathrm{F}_{0}\right), 300 \mu \mathrm{s}\left(\mathrm{F}_{\mathrm{K}}\right), 2 \mathrm{~ms}\left(\mathrm{~F}_{\mathrm{J}}\right)$, $30 \mathrm{~ms}\left(\mathrm{~F}_{\mathrm{I}}\right)$, and $\mathrm{F}_{\mathrm{M}} \approx \mathrm{F}_{\mathrm{P}}$ (the maximum fluorescence intensity) were used for the calculations of various JIP test parameters (see Appendix for their list, formulae, and biological meaning) as described by Stirbet and Govindjee (2011).

In addition to this numerical analysis, a graphical analysis of the measured fluorescence transients was performed to obtain further information on the primary photosynthetic processes. This analysis is based on the calculations of various relative variable fluorescences by the normalizations of the whole fluorescence transients: $\mathrm{W}_{\mathrm{OI}}=\left[\mathrm{F}_{\mathrm{t}}-\mathrm{F}_{0}\right] /\left[\mathrm{F}_{\mathrm{I}}-\mathrm{F}_{0}\right], \mathrm{W}_{\mathrm{OJ}}=\left[\mathrm{F}_{\mathrm{t}}-\mathrm{F}_{0}\right] /\left[\mathrm{F}_{\mathrm{J}}-\mathrm{F}_{0}\right]$, and $\mathrm{W}_{\mathrm{OK}}=\left[\mathrm{F}_{\mathrm{t}}-\mathrm{F}_{0}\right] /\left[\mathrm{F}_{\mathrm{K}}-\mathrm{F}_{0}\right] . \mathrm{F}_{\mathrm{t}}$ represents the fluorescence intensity measured at any individual time during the recording period, other $\mathrm{F}$ symbols represent fluorescence intensities at several important points of the OJIP curve and are explained above. The relative positions of the individual $\mathrm{W}_{\mathrm{OI}}$ curves (between 30 and $300 \mathrm{~ms}$ ) representing various experimental groups can be used for the comparisons of the size of the available pool of the electron acceptors at the end of the whole PETC. $\mathrm{W}_{\mathrm{OJ}}$ and $\mathrm{W}_{\mathrm{OK}}$ curves were utilized for the calculations of the difference kinetics $\left[\Delta \mathrm{W}_{\mathrm{OJ}}=\left(\mathrm{W}_{\mathrm{OJ} 20 \mathrm{HE}}-\mathrm{W}_{\mathrm{OJ} \text { CONTROL }}\right)\right.$ and $\Delta \mathrm{W}_{\mathrm{OK}}=\left(\mathrm{W}_{\mathrm{OJ} 20 \mathrm{HE}}-\right.$ $\left.\left.\mathrm{W}_{\text {OJ CONTROL }}\right)\right]$ in order to further compare the plants treated with $20 \mathrm{HE}$ with the control plants. $\Delta \mathrm{W}_{\mathrm{OJ}}$ curve reveals the so-called K-band and its position informs on a possible inactivation of the oxygen-evolving complex (OEC) of PSII. Similarly, $\Delta \mathrm{W}_{\mathrm{OK}}$ curve shows the L-band which informs on the excitonic connectivity between individual PSII units. More details on this analysis can be found, e.g., in Yusuf et al. (2010). 
Statistical analysis of the data: Each experimental variant (treatment/leaf/time of measurement) in each species was represented by eight biological replicates; means and SD were calculated and are presented, together with the original data, in the supplement. Statistical differences between the control and 20HE treatments at each time point for the respective leaves and individual plant species were determined using the Welch's two-sample $t$-test (McDonald 2014).

\section{Results}

The primary photosynthetic processes in pea were negatively influenced by $20 \mathrm{HE}$ but mostly in the younger leaves and only $168 \mathrm{~h}$ after the treatment. The electron transport from $\mathrm{Q}_{\mathrm{B}}$ to PSI acceptors (parameters $\varphi_{\mathrm{RE} 01}, \psi_{\mathrm{RE} 01}, \delta_{\mathrm{RE} 01}$, $\left.\mathrm{RE}_{01} / \mathrm{RC}, \mathrm{PI}_{\mathrm{TOTAL}}\right)$ was particularly affected in this case (Table 1). The graphical analysis of the relative variable fluorescence $\mathrm{W}_{\mathrm{OI}}$ showed that this phenomenon was probably associated with a smaller size of the pool of the PSI end electron acceptors compared to the corresponding control (the relative positions of the respective $\mathrm{W}_{\text {OI }}$ curves were markedly lower for $20 \mathrm{HE}$ and higher for control; Fig. 1). Neither the efficiency of PSII OEC nor the excitonic connectivity between individual PSII units seemed to be particularly affected by $20 \mathrm{HE}$, perhaps with the exception of the older leaves $168 \mathrm{~h}$ after the treatment (Figs. 2, 3). However, the OJIP parameters in the older pea leaves did not show any significant differences between 20HE-treated and control plants (Table 2).

The older leaves of French bean showed a positive effect of 20HE on the section of the PETC from quinone electron acceptors $\mathrm{Q}_{\mathrm{A}}$ to $\mathrm{Q}_{\mathrm{B}}$ within the PSII complex, as inferred from an increase in the values of the $\varphi_{\mathrm{E} 0}, \psi_{0}$, and $\mathrm{ET}_{0} / \mathrm{RC}$ parameters (Table 2). This was not observed for the younger leaves of this plant species (Table 1). The graphical analysis of the Chl fluorescence transient indicated that with the exception of $1 \mathrm{~h}$ after the treatment - perhaps a slightly better efficiency of PSII OEC or better excitonic connectivity between individual PSII units (as seen from the positions of the $\mathrm{K}$ - and L-bands on the respective $\Delta \mathrm{W}_{\mathrm{OJ}}$ and $\Delta \mathrm{W}_{\mathrm{OK}}$ graphs below zero; Figs. 2,3 ) could also play some role here. However, the observed changes of the positions of the K- and L-bands were not particularly consistent and the amplitude of these bands was not large; thus, the effect of $20 \mathrm{HE}$ on these components of the primary photosynthetic processes probably cannot be considered to be particularly important in this case and the same applies for the size of the pool of the PSI end electron acceptors (Fig. 1).

Neither faba bean nor soybean were much affected by the exogenous application of $20 \mathrm{HE}$, although some positive effects of this compound on several OJIP parameters were observed in the older leaves of soybean (Table 2) but usually not in the younger leaves (Table 1). Faba bean plants treated with $20 \mathrm{HE}$ displayed a smaller pool of the PSI end electron acceptors at the end of the measurement period (i.e., $168 \mathrm{~h}$ after the treatment) compared to the control plants (Fig. 1). The amplitude of the L-bands on the $\Delta \mathrm{W}_{\mathrm{OK}}$ graphs was rather small; thus, the excitonic connectivity among PSII complexes was not changed by the 20HE treatment (Fig. 3). Similar situation applied for the effect of 20HE on the performance of the OEC; although it was generally better than control in faba bean plants and worse than control in soybean plants, these changes were rather negligible (Fig. 2).

Canola was characterized by the 20HE-induced increase in the effectivity of the PETC in its older leaves and partly also in its younger leaves. However, in this case the electron transport from $\mathrm{Q}_{\mathrm{B}}$ to PSI (described by the parameters $\left.\varphi_{\mathrm{RE} 01}, \psi_{\mathrm{RE} 01}, \delta_{\mathrm{RE} 01}, \mathrm{RE}_{01} / \mathrm{RC}, \mathrm{PI}_{\mathrm{TOTAL}}\right)$ was more positively affected than the transport within PSII and the effect was observed later than that in French bean (Tables 1, 2). Although the older leaves of the 20HEtreated plants consistently showed a larger size of the pool of the PSI end electron acceptors compared to the corresponding control (as suggested by the relative positions of the respective $\mathrm{W}_{\mathrm{OI}}$ curves, which were higher for 20HE, lower for control; Fig. 1), the difference was not particularly marked. Older canola leaves of plants treated with $20 \mathrm{HE}$ also showed a better efficiency of the $\mathrm{OEC}$, as seen from the position of the K-band below zero on the respective $\Delta \mathrm{W}_{\mathrm{OJ}}$ graph, whereas for younger leaves, the opposite was true (Fig. 2). Similar to French bean, the amplitudes of the individual bands were not particularly large and the positive effect of $20 \mathrm{HE}$ on this part of the PETC would probably be only a slight one. The excitonic connectivity between individual PSII units also did not seem to be much affected by the 20HE treatment (Fig. 3).

The efficiency of the primary photosynthetic processes in leaves of radish plants mostly did not significantly respond to the 20HE treatment (Tables 1,2). The exception was the electron transport from PSII to PSI in the older leaves measured one week after the 20HE application, which was negatively affected by the treatment with this compound (parameters $\varphi_{\mathrm{RE} 01}, \psi_{\mathrm{RE} 01}, \delta_{\mathrm{RE} 01}$; Table 2 ), and the same applied for the efficiency of the OEC (Fig. 2). The reverse was true for the younger leaves at the same measurement time, which were affected by $20 \mathrm{HE}$ positively. This concerned both the performance of the OEC and the excitonic connectivity among PSII units (Figs. 2, 3), as well as the electron transport from PSII to PSI; in this case, the size of the pool of the PSI end electron acceptors could again play a positive role in the 20HE-treated plants (Table 1, Fig. 1).

The younger leaves of the 20HE-treated tomato were characterized by a more efficient absorption and trapping of the excitation energy by the LHC of the PSII complex (suggested by the changes of $\mathrm{ABS} / \mathrm{RC}, \mathrm{TP}_{0} / \mathrm{RC}$ parameters; Table 1); this was not the case of the older leaves of this plant species (Table 2). However, the OEC performance was slightly negatively affected in the younger leaves of this species, although this effect diminished with the increasing time after the treatments (the position of the $\mathrm{K}$-band above zero on the $\Delta \mathrm{W}_{\mathrm{OJ}}$ graph; Fig. 2). The overall effect of $20 \mathrm{HE}$ on the efficiency of the whole PETC $\left(\mathrm{PI}_{\mathrm{ABS}}\right.$, $\mathrm{PI}_{\text {TOTAL }}$ parameters; Table 1) was not therefore particularly significant. Other types of the graphical analysis of the OJIP curve in tomato also did not show any marked effect on either the excitonic connectivity between individual PSII 


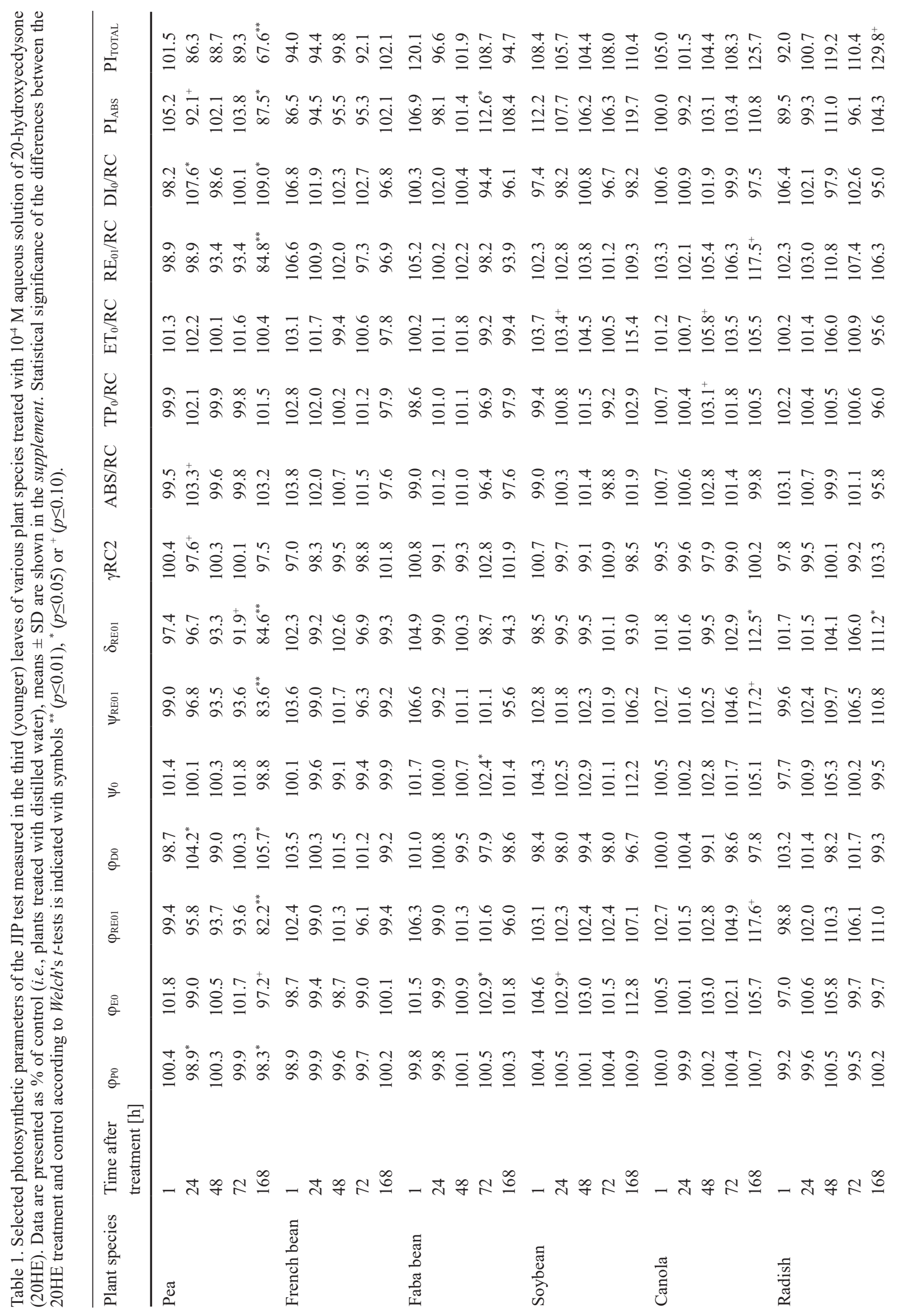




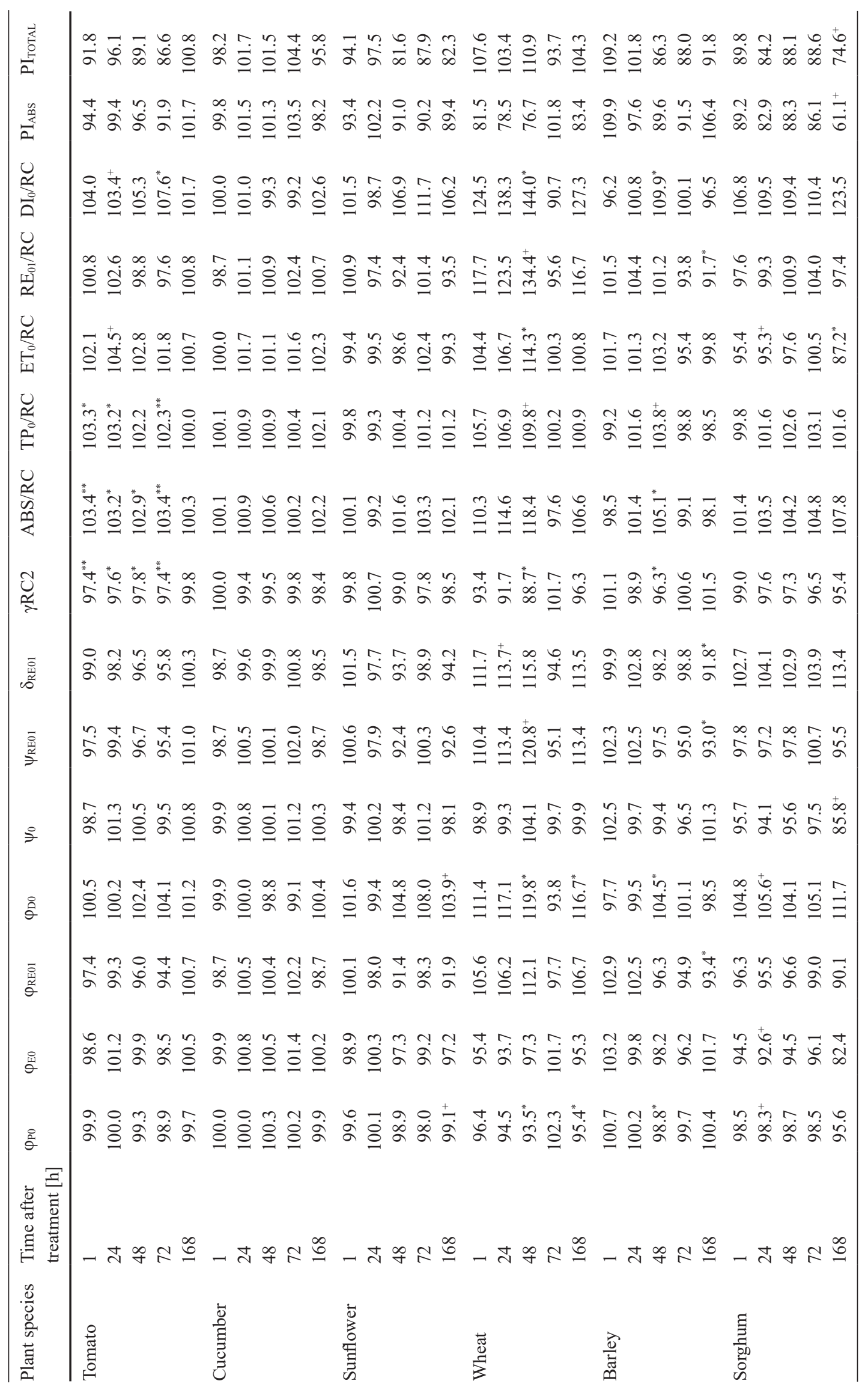




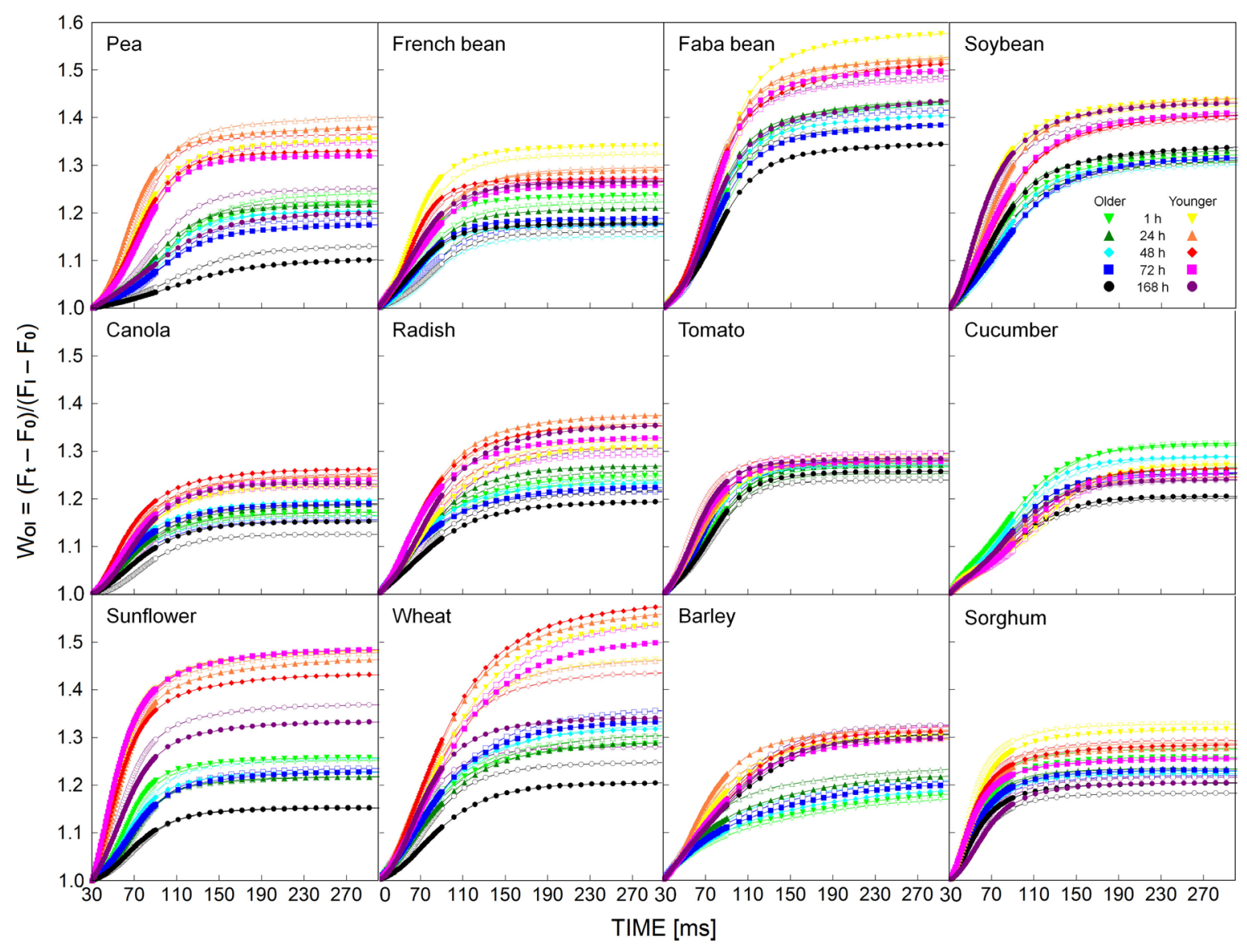

Fig. 1. The relative variable fluorescence $\mathrm{W}_{\mathrm{OI}}$ (only its part between I and P points is shown) derived from chlorophyll fluorescence measurements performed in the third (younger) and the first (older) leaves of twelve plant species treated with $10^{-4} \mathrm{M}$ aqueous solution of 20-hydroxyecdysone (20HE; solid symbols) or with distilled water (control; open symbols) and measured 1, 24, 48, 72 or 168 h after the treatment. Mean values $(n=8)$ are shown. The relative positions of the individual $\mathrm{W}_{\mathrm{OI}}$ curves for the $20 \mathrm{HE}$-treated and control plants of the respective species can be used for the comparisons of the size of the available pool of the photosystem I end electron acceptors: lower position of the respective $\mathrm{W}_{\mathrm{OI}}$ curve means a smaller size of this pool.

units or the size of the pool of the end electron acceptors (Figs. 1, 3). The primary photosynthetic processes of the cucumber plants showed no significant response to the exogenous application of $20 \mathrm{HE}$ either in older and younger leaves (Tables 1, 2; Figs. 1-3).

The older leaves of 20HE-treated sunflower (but not the younger ones) also displayed an overly efficient trapping of the excitation energy by the PSII LHC (the $\mathrm{ABS} / \mathrm{RC}, \mathrm{TP}_{0} / \mathrm{RC}$ parameters; Tables 1,2$)$. However, in this case, this was probably not followed by an equally efficient transformation of this energy into the energy of the electron transport and resulted instead in a rather high dissipation of the excess excitation energy $\left(\varphi_{\mathrm{D} 0}, \mathrm{DI}_{0} / \mathrm{RC}\right.$ parameters; Table 2). Low excitonic connectivity between the individual PSII units (inferred from the position of the L-band above zero together with its rather large amplitude on the $\Delta \mathrm{W}_{\mathrm{OK}}$ graph; Fig. 3) could be one of the possible causes for the overall suboptimal performance of $20 \mathrm{HE}-$ treated sunflower. The OEC effectivity was also negatively affected in the older leaves of this species, as can be seen from the position - and amplitude - of the K-band on the graph of $\Delta \mathrm{W}_{\mathrm{OJ}}$ (Fig. 2). Taken together, all these phenomena could be the reason for the observed negative effect of 20HE on the efficiency of the whole PETC in the older sunflower leaves $\left(\mathrm{PI}_{\mathrm{ABS}}, \mathrm{PI}_{\mathrm{TO} \text { TAL }}\right.$ parameters; Table 2$)$.

Besides sunflower, wheat was the plant species most affected by the $20 \mathrm{HE}$ application. However, in this case, the effect was particularly prominent in the younger leaves and the most effective time was $48 \mathrm{~h}$ after the treatment (Tables 1, 2; Figs. 1-3). Both the OEC performance and the excitonic connectivity among individual PSII units was strongly negatively influenced by 20HE (Figs. 2, 3), which was reflected in the diminished value of the OJIP parameters pertaining to the PSII function (Table 1). It also seems that the efficiency of the transformation of trapped excitation energy into the energy of the electron transport was diminished in this case and, instead of the electron transport, high dissipation of the excess excitation energy into nonphotosynthetic processes took place (increase in the values of the $\varphi_{\mathrm{D} 0}, \mathrm{DI}_{0} / \mathrm{RC}$ parameters; Table 1$)$. On the other hand, the size of the pool of the PSI end electron acceptors increased due to the 20HE treatment (Fig. 1), 


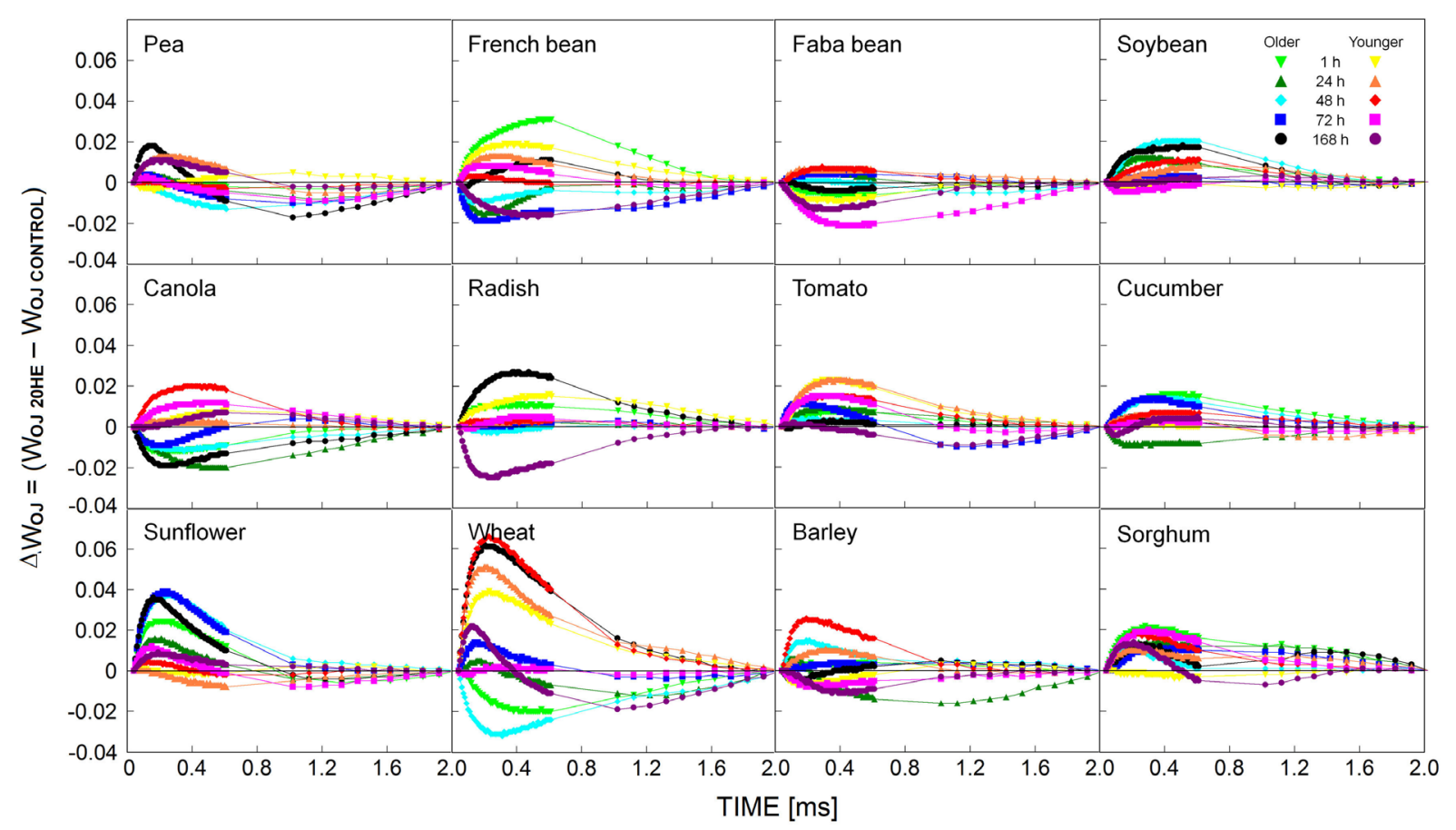

Fig. 2. The difference kinetics $\Delta \mathrm{W}_{\mathrm{OJ}}$ derived from chlorophyll fluorescence measurements performed in the third (younger) and the first (older) leaves of twelve plant species treated with $10^{-4} \mathrm{M}$ aqueous solution of 20-hydroxyecdysone (20HE) or with distilled water (control) and measured 1, 24, 48, 72 or $168 \mathrm{~h}$ after the treatment. Mean values $(n=8)$ are shown. $\Delta \mathrm{W}_{\mathrm{OJ}}$ reveals the so-called $\mathrm{K}$-band of the OJIP analysis for the 20HE-treated plants; control plants are represented by zero point of the $y$-axis in the respective graphs. The position of the K-band above zero means that the oxygen-evolving complex of photosystem II was negatively affected by the $20 \mathrm{HE}$ treatment compared to the control, the position below zero signifies the reverse situation.

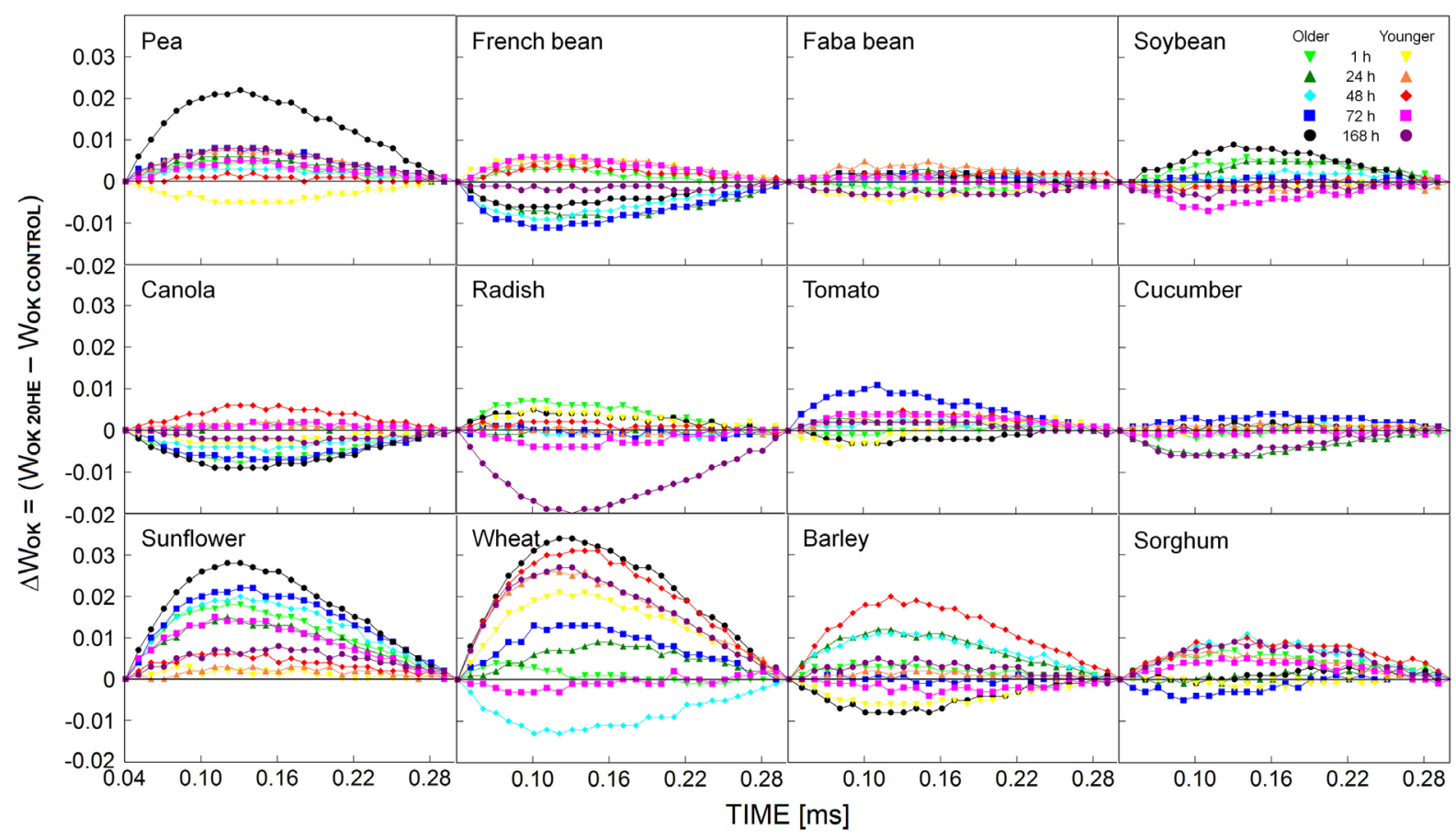

Fig. 3. The difference kinetics $\Delta \mathrm{W}_{\text {Ок }}$ derived from chlorophyll fluorescence measurements performed in the third (younger) and the first (older) leaves of twelve plant species treated with $10^{-4} \mathrm{M}$ aqueous solution of 20-hydroxyecdysone (20HE) or with distilled water (control) and measured 1, 24, 48, 72 or $168 \mathrm{~h}$ after the treatment. Mean values $(n=8)$ are shown. $\Delta \mathrm{W}_{\mathrm{OK}}$ reveals the so-called L-band of the OJIP analysis for the 20HE-treated plants; control plants are represented by zero point of the $y$-axis in the respective graphs. The position of the L-band above zero means that the excitonic connectivity among individual photosystem II units was negatively affected by the $20 \mathrm{HE}$ treatment compared to the control, the position below zero signifies the reverse situation. 


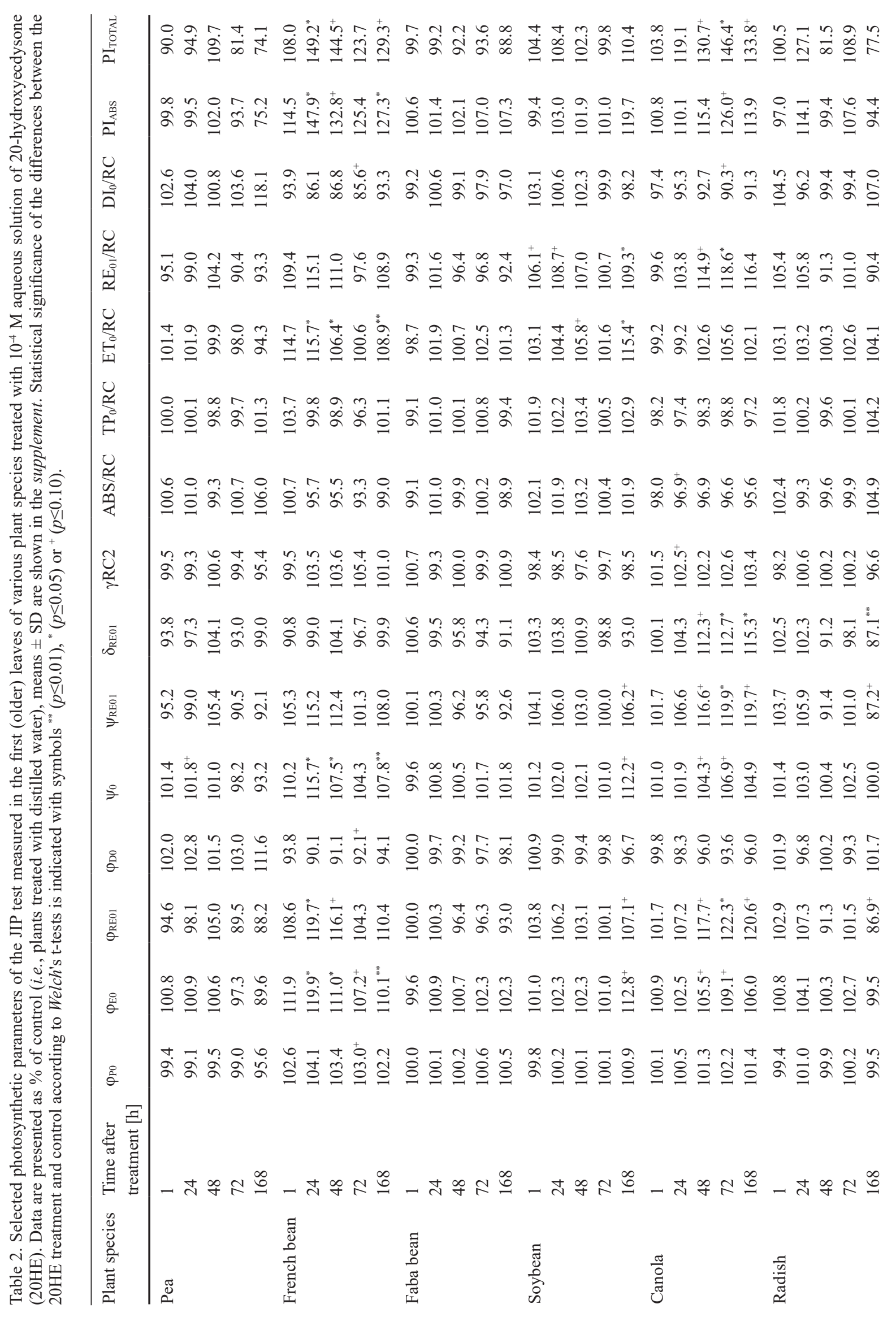




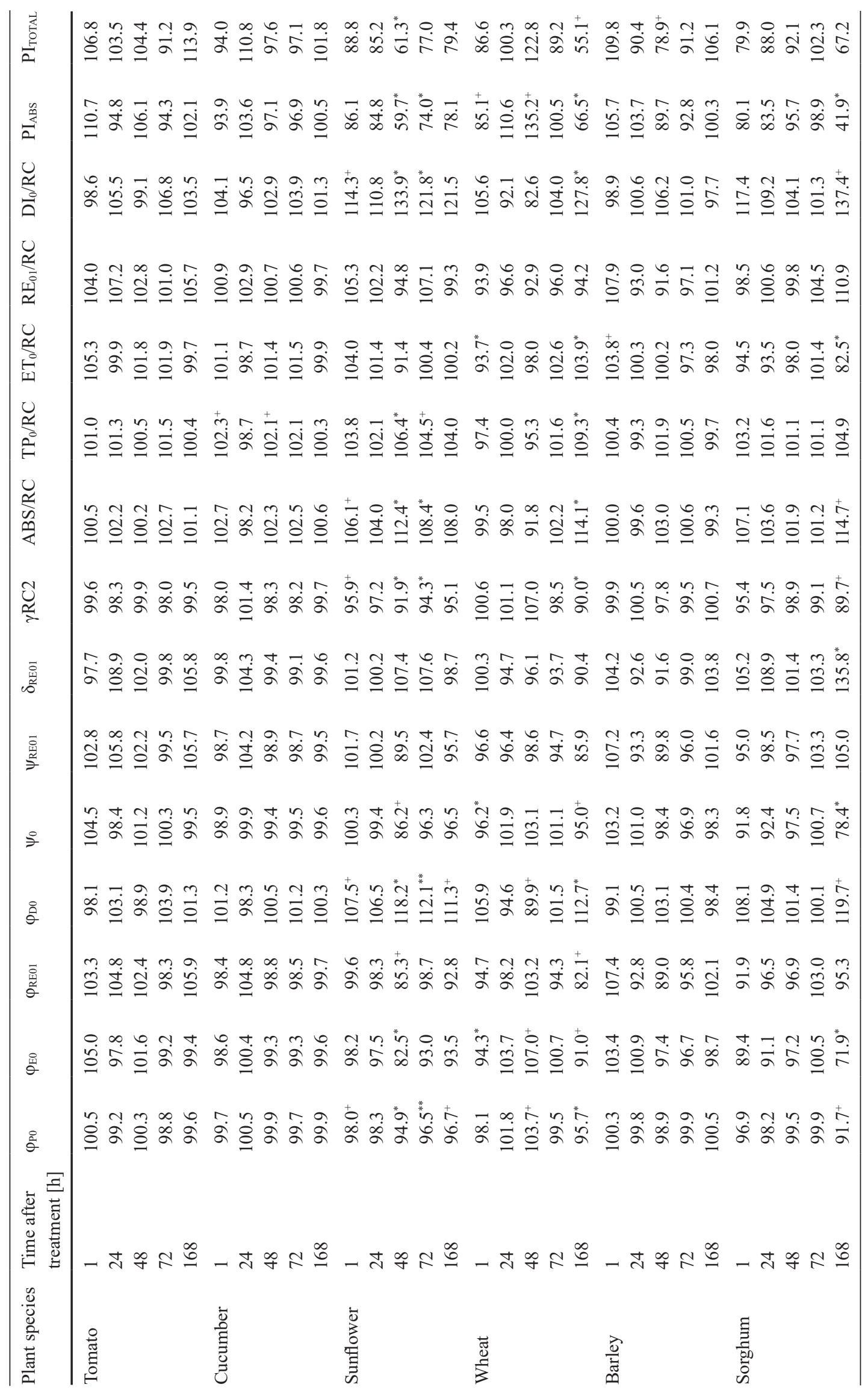


which was probably reason for the observed increase in the values of the OJIP parameters associated with PSI performance (Table 1). The effect of 20HE on the PETC in the older wheat leaves was usually less prominent than that in the younger ones with the exception of the measurements made one week after the treatment (Table 2). The overall performance of all components of the PETC was very negatively affected in this case (Table 2, Figs. 1-3).

Neither barley nor sorghum plants showed any consistent trend in the response of their PETC to 20HE (Tables 1, 2; Figs. 1-3). Sorghum perhaps responded more negatively, particularly at the end of the experimental period, but the changes in the values of the OJIP parameters were usually nonsignificant (with the exception of leaves $168 \mathrm{~h}$ after the treatment) and the positions of the respective curves on the $\mathrm{W}_{\mathrm{OI}}, \Delta \mathrm{W}_{\mathrm{OJ}}$, and $\Delta \mathrm{W}_{\mathrm{OK}}$ graphs changed only slightly with the 20HE treatment of the plants (Tables 1, 2; Figs. 1-3).

\section{Discussion}

Based on our results described in this paper, it seems that $20 \mathrm{HE}$ can truly play some role in the regulation of the efficiency of the PETC in plants as suggested by our previous experiments with spinach and maize (Rothová et al. 2014). However, the situation is far from being simple. Evidently, the influence of ECs on the efficiency of the primary photosynthetic processes is extremely diverse, without any common trend across plant kingdom. At this time, it is certainly not clear how exactly ECs function in higher plants. The in vitro study of Uhlík et al. (2008) demonstrated that ECs could directly bind to at least one photosynthetic protein (ribulose-1,5-bisphosphate carboxylase/oxygenase, which is the main protein of the photosynthetic carbon fixation cycle). However, in our opinion, the more probable idea is that ECs in plants are somehow interconnected with another group of plant oxysterols, i.e., BRs. BRs have been proposed to act as more immediate regulators of the PETC and available evidence suggests that this could be indeed true. Studies show that various genes coding for components of the PETC belong to the group that is regulated at least on the transcriptional level by BRs (Komatsu et al. 2010, Sun et al. 2010, Efimova et al. 2012a,b; 2017). BRs also participate in the regulation of the organization of the chloroplast thylakoid membrane system, which is the place where the PETC occurs (Krumova et al. 2013, Dobrikova et al. 2014, Schröder et al. 2014, Liu et al. 2016). The role of BRs in the regulation of the PETC could be also indirectly associated (by feedback processes) with the regulation of the photosynthetic carbon fixation cycle (which is probably mainly related to BR regulation of the chloroplast redox state; Jiang et al. 2012a,b; 2013; Cheng et al. 2014). The topic of BRs and their possible role in the regulation of the primary photosynthetic processes has been reviewed by e.g., Holá (2011).

The level of cellular processes, on which could ECs interact with BRs, remains to be identified. ECs could substitute for BRs in their perception/signalling pathway and thus mimic their effects; Golovatskaya (2004) suggested that these two sterol groups could share the same receptor. However, Thussagunpanit et al. (2018) reported that although synthetic 20HE derivatives with some structural similarity to BRs could at least partly replace BRs in the regulation of their signaling, 20HE per se did not function in this manner and the direct substitution of $20 \mathrm{HE}$ for BRs at the binding site of BR receptor therefore seems unlikely. Another possibility is the regulation of BR contents by ECs (and/or vice versa). Both groups of these oxysterols share initial components of their biosynthetic pathways up to the squalene formation (Tarkowská and Strnad 2018) and feedback control of their biosynthesis in plants by their respective amounts occurs (Tanaka et al. 2005, Bakrim et al. 2008). Any treatment of plants with ECs/BRs could thus result in the altered expression of the respective biosynthetic genes or genes coding for proteins responsible for their metabolism. We have shown that exogenously applied BRs reduce the amount of ECs in spinach leaves (Kamlar et al. 2015), and another (still preliminary) analysis performed by our colleagues with garden cress demonstrated that the treatment of plants with 20HE can result in reduced BR contents (Krampolová 2017). This indeed suggests that there can be some reciprocal connection between $\mathrm{BR}$ and $\mathrm{EC}$ biosynthesis and/or metabolism, which could influence the endogenous contents of these oxysterols.

In our opinion, such mutually repressive influence on $\mathrm{BR}$ and EC contents in plants seems at this time the most probable mechanism by which ECs could affect the primary photosynthetic processes. It could also perhaps explain the observed interspecific differences, because different plant species contain different amounts of both BRs and ECs (Dinan et al. 2001, Bajguz 2011, http://ecdybase.org/). Simultaneous application of BRs and ECs cancelled their individual effects on the PETC performance in maize and spinach (Rothová et al. 2014). It is thus possible that the normal function of the photosynthetic apparatus requires a very precise ratio of both oxysterol types and any disbalance (such as that caused by an exogenous EC application) can change the way BRs affect the primary photosynthetic processes. It certainly seems that in some plant families (e.g., Fabaceae and Brassicaceae), the PETC is more sensitive to exogenously applied BRs than in others (e.g., Solanaceae and Poaceae) and interspecific differences in the response of photosynthesis to BRs can exist even within the same plant family (Holá 2011). It is also possible that interspecific differences in leaf anatomy and morphology affect the entry of exogenously applied oxysterols into leaves, thus causing differences in the amounts of these compounds that truly get inside and can interact with receptors or other proteins, even if the same concentration of sterol solution was originally used for the treatment.

The observed differences between the response of the PETC in the older and younger leaves to 20HE are another interesting finding. Our previous results with maize and spinach (Rothová et al. 2014) showed that the more marked effects of $20 \mathrm{HE}$ were found in the older leaves compared to the younger ones. In the present study, we found 
that this does not necessarily apply for all plant species (e.g., for French bean, canola, and sunflower, the stronger response to $20 \mathrm{HE}$ was in the older leaves, but the situation was opposite for wheat, pea, and tomato). Presuming that ECs in some way affect the BR-induced regulation of the primary photosynthetic processes, this dependance on the developmental state of the leaves could be related to the differences in the contents of endogenous ECs and/or BRs between different leaf insertions (shown e.g., by Bakrim et al. 2008, Kamlar et al. 2015 or Janeczko and Swaczynová 2010). The stronger response to $20 \mathrm{HE}$ observed in the older leaves of some species and the general observation that the effects of $20 \mathrm{HE}$ were usually more pronounced with the increase of time after the treatments (which also agrees with our previous finding in maize and spinach; Rothová et al. 2014), could be perhaps associated with the beginning of senescence or even at least slightly stressed state of the older leaves. This could apply particularly to French bean and canola, where the absolute values of the $\varphi_{\mathrm{P} 0}$ parameter (which is usually considered to be a good indicator of plant stress) in the older leaves of our plants nontreated with $20 \mathrm{HE}$ indicated suboptimum performance of the PSII (supplement). The influence of BRs on the PETC is certainly always much more pronounced in plants stressed by some unfavourable environmental factor than that in plants grown under optimum conditions (Holá 2011) and the older leaves could be perhaps more sensitive to any disbalance of the BR contents caused by the $20 \mathrm{HE}$ treatment. However, at this time we do not have any simple explanation for the situation in wheat, pea or tomato. The only thing that seems to be clear is the absence of any evident association between the developmental differences in the response of primary photosynthetic processes to $20 \mathrm{HE}$ and the most affected components of the PETC.

The exact cause(s) for the interspecific variability in different responses of various parts of the PETC to the treatment of plants with $20 \mathrm{HE}$ remains for the present unknown. We found such variability already in our previous study with maize and spinach, which differed e.g., in the response of the LHC, OEC, and PSII complexes but showed more similar response of the PSI part of the PETC (Rothová et al. 2014) and it manifested itself even more in our current experiments. Only a few plant species (Arabidopsis, pea, barley, rape) have been yet examined in more detail regarding the effect of plant sterols on the individual components of the PETC and only BRs have been assessed in this respect. The experimental evidence available thus far for BRs seems to suggest that the PSI complex should be more sensitive to the imbalances in BR content than PSII (Krumova et al. 2011, 2013; Dobrikova et al. 2013, 2014). Besides our previous study (Rothová et al. 2014), we now found that PSI-associated parts of the PETC were affected by $20 \mathrm{HE}$ also in pea, canola, and wheat. However, the OEC component of the PSII complex also seems to be an important target, unlike the electron transport in the other parts of the PSII complex (Janeczko et al. 2005, Skoczowski et al. 2011, Dobrikova et al. 2014, Rothová et al. 2014, Pociecha et al. 2016). Our experiments showed that the OEC can be indeed influenced by $20 \mathrm{HE}$, e.g., in sunflower and wheat and, to a lesser extent, probably also in canola and tomato. However, the efficiency of the electron transport between quinone acceptors $\mathrm{Q}_{\mathrm{A}}$ and $\mathrm{Q}_{\mathrm{B}}$ also changed in French bean, which has not been previously observed in any other plant species. It also seems that BRs can induce changes in the macroorganisation of the light-harvesting antennae of PSII and thus impact the efficiency of photon trapping (Dobrikova et al. 2014). Again, exogenous treatment of two of our experimental plant species (sunflower, tomato) with $20 \mathrm{HE}$ resulted in a more efficient photon trapping. However, as this was not followed by a similarly efficient energy transfer within the PETC (and sometimes was also accompanied by diminished efficiency of the excitation connectivity among individual PSII units), the excess excitation energy had to be dissipated by nonphotosynthetic processes and did not necessarily result in a positive effect on the PETC.

Conclusions: The results of our analysis of the effects of $20 \mathrm{HE}$ on the efficiency of primary photosynthetic processes in twelve plant species offer evidence that ECs can act not only as protective compounds against herbivorous insects and nematodes but participate also in the regulation of other physiological processes occuring in plants, such as photosynthesis. However, this role depends on a particular plant species, can be influenced by the developmental state of leaves, and can involve different components of the PETC in different plant species. Thus, our experiments brought a new information that opens several new questions regarding the potential EC action in plants. Plant ECs certainly deserve more attention than they are currently receiving and their biological function should be studied further and in more detail. Additionally, in order to understand the involvement of ECs in various aspects of plant life, we certainly should not depend on information obtained from just a few model species.

\section{References}

Bajguz A.: Brassinosteroids - occurence and chemical structures in plants. - In: Hayat S., Ahmad A. (ed.): Brassinosteroids: A Class of Plant Hormone. Pp. 1-27. Springer, Dordrecht 2011.

Bajguz A., Dinan L.: Effects of ecdysteroids on Chlorella vulgaris. - Physiol. Plantarum 121: 349-357, 2004.

Bajguz A., Godlewska-Zylkiewicz B.: Protective role of 20-hydroxyecdysone against lead stress in Chlorella vulgaris cultures. - Phytochemistry 65: 711-720, 2004.

Bajguz A., Koronka A.: Effect of ecdysone application on the growth and biochemical changes in Chlorella vulgaris cells. Plant Physiol. Bioch. 39: 707-715, 2001.

Bakrim A., Lamhamdi M., Sayah F., Chib F.: Effects of plant hormones and 20-hydroxyecdysone on tomato (Lycopersicum esculentum) seed germination and seedlings growth. - Afr. J. Biotechnol. 6: 2792-2802, 2007.

Bakrim A., Maria A., Sayah F. et al:: Ecdysteroids in spinach (Spinacia oleracea L.): biosynthesis, transport and regulation of levels. - Plant Physiol. Bioch. 46: 844-854, 2008.

Cheng F., Zhou Y.H., Xia X.J. et al.: Chloroplastic thioredoxin- $f$ and thioredoxin- $m 1 / 4$ play important roles in brassinosteroidsinduced changes in $\mathrm{CO}_{2}$ assimilation and cellular redox homeostasis in tomato. - J. Exp. Bot. 65: 4335-4347, 2014. 
Dinan L., Savchenko T., Whiting P.: On the distribution of phytoecdysteroids in plants. - Cell Mol. Life Sci. 58: 11211132, 2001.

Dobrikova A.G., Vladkova R.S., Rashkov G.D. et al.: Effects of exogenous 24-epibrassinolide on the photosynthetic membranes under non-stress conditions. - Plant Physiol. Bioch. 80: 75-82, 2014.

Dobrikova A.G., Vladkova R.S., Stanoeva D. et al.: Effects of 24-epibrassinolide pre-treatment on UV-B-induced changes in the pigment content of pea leaves. - C. R. Acad. Bulg. Sci. 66: 543-550, 2013.

Efimova M.V., Kusnetsov V.V., Kravtsov A.K. et al.: Expression of plastid genome and development of Arabidopsis thaliana with disturbed synthesis of brassinosteroids. - Russ. J. Plant Physl+ 59: 28-34, 2012a.

Efimova M.V., Kusnetsov V.V., Kravtsov A.K. et al.: Regulation of the transcription of plastid genes in plants by brassinosteroids. - Dokl. Biol. Sci. 445: 272-275, 2012b.

Efimova M.V., Vaňková R., Kusnetsov V.V. et al.: Effects of 24-epibrassinolide and green light on plastid gene transcription and cytokinin content of barley leaves. - Steroids 120: 32-40, 2017.

Golovatskaya I.F.: Effect of ecdysterone on morphological and physiological processes in plants. - Russ. J. Plant. Physl+ 51: 452-458, 2004.

Haitov B., Mamadalieva N., Egamberdieva D.: Plant-derived 20-hydroxyecdysone alleviates salt stress in cotton (Gossypium hirsutum L.) seedlings. - Asian Australasian J. Plant. Sci. Biotechnol. 7: 39-42, 2013.

Holá D.: Brassinosteroids and photosynthesis. - In: Hayat S., Ahmad A. (ed.): Brassinosteroids: A Class of Plant Hormone. Pp. 143-192. Springer, Dordrecht 2011.

Holá D., Kočová M., Rothová O. et al.: Exogenously applied 20-hydroxyecdysone increases the net photosynthetic rate but does not affect the photosynthetic electron transport or the content of photosynthetic pigments in Tetragonia tetragonioides L. - Acta Physiol. Plant. 35: 3489-3495, 2013.

Janeczko A., Kościelniak J., Pilipowicz M. et al:: Protection of winter rape photosystem 2 by 24-epibrassinolide under cadmium stress. - Photosynthetica 43: 293-298, 2005.

Janeczko A., Swaczynová J.: Endogenous brassinosteroids in wheat treated with 24-epibrassinolide. - Biol. Plantarum 54: 477-482, 2010.

Jiang Y.P., Cheng F., Zhou Y.H. et al.: Brassinosteroid-induced $\mathrm{CO}_{2}$ assimilation is associated with increased stability of redox-sensitive photosynthetic enzymes in the chloroplasts in cucumber plants. - Biochem. Bioph. Res. Co. 426: 390-394, 2012a.

Jiang Y.P., Cheng F., Zhou Y.H. et al.: Cellular glutathione redox homeostasis plays an important role in the brassinosteroid induced increase in $\mathrm{CO}_{2}$ assimilation in Cucumis sativus. New Phytol. 194: 932-943, 2012b.

Jiang Y.P., Huang L.F., Cheng F. et al.: Brassinosteroids accelerate recovery of photosynthetic apparatus from cold stress by balancing the electron partitioning, carboxylation and redox homeostasis in cucumber. - Physiol. Plantarum 148: 133-145, 2013.

Kamlar M., Rothová O., Salajková Š. et al.: The effect of exogenous 24-epibrassinolide on the ecdysteroid content in the leaves of Spinacia oleracea L. - Steroids 97: 107-112, 2015.

Khamsuk O., Sonjaroon W., Suwanwong S. et al:: Effects of 24-epibrassinolide and the synthetic brassinosteroid mimic on chili pepper under drought. - Acta Physiol. Plant. 40: 106, 2018.

Komatsu T., Kawaide H., Saito C. et al.: The chloroplast protein BPG2 functions in brassinosteroid mediated posttranscriptional accumulation of chloroplast rRNA. - Plant J. 61: 409-422, 2010.

Krampolová E.: [Brassinosteroids and phytoecdysteroids crosstalk in planta.] B. Sc. Thesis, Palacký University in Olomouc, Faculty of Science, Olomouc, Czech Republic 2017. [In Czech] https://theses.cz/id/ct9iov

Krumova S., Zhiponova M., Dankov K. et al.: Brassinosteroids regulate the thylakoid membrane architecture and the photosystem II function. - J. Photoch. Photobio. B 126: 97-104, 2013.

Krumova S., Zhiponova M., Dankov K. et al.: Effects of enhanced brassinosteroid perception on photosynthetis in Arabidopsis thaliana line BRIOE. - C. R. Acad. Bulg. Sci. 64: 967-972, 2011.

Lamhamdi M., Lafont R., Rharrabe K. et al.: 20-Hydroxyecdysone protects wheat seedlings (Triticum aestivum L.) against lead stress. - Plant Physiol. Bioch. 98: 64-71, 2016.

Li J.T., Han X.P., Tang L. et al.: 20-Hydroxyecdysone protects wheat seedlings from salt stress. - Arch. Biol. Sci. 70: 379386,2018

Liu X., Feng Z.M., Zhou C.L. et al.: Brassinosteroid (BR) biosynthetic gene lhdd10 controls late heading and plant height in rice (Oryza sativa L.). - Plant Cell Rep. 35: 357$368,2016$.

McDonald J.H.: Handbook of Biological Statistics. $3^{\text {rd }}$ Edition. Pp. 126-130. Sparky House Publishing, Baltimore 2014.

Moreau R.A., Nyström L., Whitaker B.D. et al.: Phytosterols and their derivatives: Structural diversity, distribution, metabolism, analysis, and health-promoting uses. - Prog. Lipid Res. 70: 35-61, 2018.

Moreau R.A., Whitaker B.D., Hicks K.B.: Phytosterols, phytostanols, and their conjugates in foods: structural diversity, quantitative analysis, and health-promoting uses. Prog. Lipid Res. 41: 457-500, 2002.

Pociecha E., Dziurka M., Oklešt'ková J., Janeczko A.: Brassinosteroids increase winter survival of winter rye (Secale cereale L.) by affecting photosynthetic capacity and carbohydrate metabolism during the cold acclimation process. - Plant Growth Regul. 80: 127-135, 2016.

Rothová O., Holá D., Kočová M. et al.: 24-epibrassinolide and 20-hydroxyecdysone affect photosynthesis differently in maize and spinach. - Steroids 85: 44-57, 2014.

Schröder F., Lisso J., Obata T. et al.: Consequences of induced brassinosteroid deficiency in Arabidopsis leaves. - BMC Plant Biol. 14: 309, 2014.

Skoczowski A., Janeczko A., Gullner G. et al.: Response of brassinosteroid-treated oilseed rape cotyledons to infection with the wild type and HR-mutant of Pseudomonas syringae or with P. fluorescence. - J. Therm. Anal. Calorim. 104: 131$139,2011$.

Sonjaroon W., Jutamanee K., Khamsuk O. et al:: Impact of brassinosteroid mimic on photosynthesis, carbohydrate content and rice seed set at reproductive stage under heat stress. - Agric. Nat. Resour. 52: 234-240, 2018.

Sonjaroon W., Kaveeta L., Chai-arree W. et al.: Exogenous 7,8-dihydro-8 $\alpha$-20-hydroxyecdysone application improves antioxidative enzyme system, photosynthesis, and yield in rice under high-temperature condition. - Acta Physiol. Plant. 38: 202, 2016.

Stirbet A., Govindjee: On the relation between the Kautsky effect (chlorophyll $a$ fluorescence induction) and photosystem II: Basics and applications of the OJIP fluorescence transient. J. Photoch. Photobio. B 104: 236-257, 2011.

Strasser R.J., Tsimilli-Michael M., Srivastava A.: Analysis of the chlorophyll $a$ fluorescence transient. - In: Papageorgiou G.C., 
Govindjee (ed.): Chlorophyll $a$ Fluorescence: A Signature of Photosynthesis. Advances in Photosynthesis and Respiration. Pp. 321-362. Springer, Dordrecht 2004.

Sun Y., Fan X.Y., Cao D.M. et al.: Integration of brassinosteroid signal transduction with the transcription network for plant growth regulation in Arabidopsis. - Dev. Cell 19: 765-777, 2010.

Tanaka K., Asami T., Yoshida S. et al.: Brassinosteroid homeostasis in Arabidopsis is ensured by feedback expressions of multiple genes involved in its metabolism. - Plant Physiol. 138: 1117-1125, 2005.

Tarkowská D., Strnad M.: Plant ecdysteroids: plant sterols with intriguing distributions, biological effects and relations to plant hormones. - Planta 244: 545-555, 2016.

Tarkowská D., Strnad M.: Isoprenoid-derived plant signaling molecules: biosynthesis and biological importance. - Planta 247: 1051-1066, 2018.

Thiem B., Kikowska M., Maliński M.P. et al.: Ecdysteroids: production in plant in vitro cultures. - Phytochem. Rev. 16: 603-622, 2017.

Thussagunpanit J., Jutamanee K., Homvisasevongsa S. et al.: Characterization of synthetic ecdysteroid analogues as functional mimics of brassinosteroids in plant growth. J. Steroid Biochem. Mol. Biol. 172: 1-8, 2018.

Thussagunpanit J., Jutamanee K., Kaveeta L. et al.: Comparative effects of brassinosteroid and brassinosteroid mimic on improving photosynthesis, lipid peroxidation, and rice seed set under heat stress. - J. Plant Growth Regul. 34: 320-331, $2015 \mathrm{a}$.

Thussagunpanit J., Jutamanee K., Sonjaroon W. et al.: Effects of brassinosteroid and brassinosteroid mimic on photosynthetic efficiency and rice yield under heat stress. - Photosynthetica 53: 312-320, 2015b.

Uhlík O., Kamlar M., Kohout L. et al.: Affinity chromatography reveals $\mathrm{RuBisCO}$ as an ecdysteroid-binding protein. - Steroids 73: 1433-1440, 2008.

Valitova J.N., Sulkarnayeva A.G., Minibayeva F.V.: Plant sterols: diversity, biosynthesis and physiological functions. Biochemistry-Moscow+ 81: 819-834, 2016.

Yusuf M.A., Kumar D., Rajwanshi R. et al.: Overexpression of $\gamma$-tocopherol methyl transferase gene in transgenic Brassica juncea plants alleviates abiotic stress: Physiological and chlorophyll a fluorescence measurements. - BBABioenergetics 1797: 1428-1438, 2010.

Appendix. Selected photosynthetic parameters of the JIP test derived from the measurements of the polyphasic rise of chlorophyll $a$ fluorescence transient. $\mathrm{F}_{0}$ - the initial fluorescence intensity (at $40 \mu \mathrm{s}$ ), $\mathrm{F}_{\mathrm{K}}$ - the fluorescence intensity at the K-step (at $300 \mu \mathrm{s}$ ), $\mathrm{F}_{\mathrm{J}}$ - the fluorescence intensity at the J-step (at $2 \mathrm{~ms}$ ), $\mathrm{F}_{\mathrm{I}}$ - the fluorescence intensity at the I-step (at $30 \mathrm{~ms}$ ), $\mathrm{F}_{\mathrm{M}} \approx \mathrm{F}_{\mathrm{P}}-$ the maximum fluorescence intensity, PSI - photosystem I, PSII - photosystem II, RC - reaction center.

\begin{tabular}{|c|c|c|}
\hline Parameter & Definition, biological meaning & Formula \\
\hline $\mathrm{V}_{\mathrm{J}}$ & Relative variable fluorescence at the J-step & $\left(\mathrm{F}_{\mathrm{J}}-\mathrm{F}_{0}\right) /\left(\mathrm{F}_{\mathrm{M}}-\mathrm{F}_{0}\right)$ \\
\hline $\mathrm{V}_{\mathrm{I}}$ & Relative variable fluorescence at the I-step & $\left(\mathrm{F}_{\mathrm{I}}-\mathrm{F}_{0}\right) /\left(\mathrm{F}_{\mathrm{M}}-\mathrm{F}_{0}\right)$ \\
\hline $\mathrm{M}_{0}$ & Approximated initial slope of the fluorescence transient & $4\left(\mathrm{~F}_{\mathrm{K}}-\mathrm{F}_{0}\right) /\left(\mathrm{F}_{\mathrm{M}}-\mathrm{F}_{0}\right)$ \\
\hline$\varphi_{\mathrm{P} 0}$ & Maximum quantum yield of primary PSII photochemistry & $\left(\mathrm{F}_{\mathrm{M}}-\mathrm{F}_{0}\right) / \mathrm{F}_{\mathrm{M}}$ \\
\hline$\varphi_{\mathrm{E} 0}$ & Quantum yield of electron transport flux from $\mathrm{Q}_{\mathrm{A}}$ to $\mathrm{Q}_{\mathrm{B}}$ & {$\left[1-\left(\mathrm{F}_{0} / \mathrm{F}_{\mathrm{M}}\right)\right]\left(1-\mathrm{V}_{\mathrm{J}}\right)$} \\
\hline$\varphi_{\mathrm{RE} 01}$ & Quantum yield of electron transport flux until the PSI electron acceptors & $1-\left(\mathrm{F}_{\mathrm{I}} / \mathrm{F}_{\mathrm{M}}\right)$ \\
\hline$\varphi_{\mathrm{D} 0}$ & Quantum yield of energy dissipation & $\mathrm{F}_{0} / \mathrm{F}_{\mathrm{M}}$ \\
\hline$\psi_{\mathrm{E} 0}$ & Efficiency/probability with which a PSII trapped electron is transferred from $\mathrm{Q}_{\mathrm{A}}$ to $\mathrm{Q}_{\mathrm{B}}$ & $1-\mathrm{V}_{\mathrm{J}}$ \\
\hline$\psi_{\mathrm{RE} 01}$ & $\begin{array}{l}\text { Efficiency/probability with which a PSII trapped electron is transferred until PSI } \\
\text { acceptors }\end{array}$ & $1-\mathrm{V}_{\mathrm{I}}$ \\
\hline$\delta_{\text {RE01 }}$ & Efficiency/probability with which an electron from $\mathrm{Q}_{\text {в }}$ is transferred until PSI acceptors & $\left(1-V_{\mathrm{I}}\right) /\left(1-\mathrm{V}_{\mathrm{J}}\right)$ \\
\hline$\gamma \mathrm{RC} 2$ & Probability that a PSII chlorophyll functions as RC & $1 /(\mathrm{ABS} / \mathrm{RC}+1)$ \\
\hline $\mathrm{ABS} / \mathrm{RC}$ & Average absorbed photon flux per PSII RC (apparent antenna size of an active PSII) & $\left(\mathrm{M}_{0} / \mathrm{V}_{\mathrm{J}}\right)\left(1 / \varphi_{\mathrm{P} 0}\right)$ \\
\hline $\mathrm{TP}_{0} / \mathrm{RC}$ & Maximum trapped exciton flux per PSII & $\mathrm{M}_{0} / \mathrm{V}_{\mathrm{J}}$ \\
\hline $\mathrm{ET}_{0} / \mathrm{RC}$ & Electron transport flux from $\mathrm{Q}_{\mathrm{A}}$ to $\mathrm{Q}_{\mathrm{B}}$ per PSII & $\left(\mathrm{M}_{0} / \mathrm{V}_{\mathrm{J}}\right) \psi_{\mathrm{E} 0}$ \\
\hline $\mathrm{RE}_{01} / \mathrm{RC}$ & Electron transport flux until PSI acceptors per PSII & $\left(\mathrm{M}_{0} / \mathrm{V}_{\mathrm{J}}\right) \psi_{\mathrm{RE} 01}$ \\
\hline $\mathrm{DI}_{0} / \mathrm{RC}$ & Dissipated energy flux per PSII & $(\mathrm{ABS} / \mathrm{RC})-\left(\mathrm{TP}_{0} / \mathrm{RC}\right)$ \\
\hline $\mathrm{PI}_{\mathrm{ABS}}$ & $\begin{array}{l}\text { Performance index for energy conservation from photons absorbed by PSII antenna, } \\
\text { to the reduction of } \mathrm{Q}_{\mathrm{B}}\end{array}$ & $\begin{array}{l}{[1 /(\mathrm{ABS} / \mathrm{RC})]\left[\varphi_{\mathrm{P} 0} /\left(1-\varphi_{\mathrm{P} 0}\right)\right.} \\
{\left[\psi_{\mathrm{E} 0} /\left(1-\psi_{\mathrm{E} 0}\right)\right]}\end{array}$ \\
\hline $\mathrm{PI}_{\text {TOTAL }}$ & $\begin{array}{l}\text { Performance index for energy conservation from photons absorbed by PSII antenna, } \\
\text { until the reduction of PSI acceptors }\end{array}$ & $\mathrm{PI}_{\mathrm{ABS}}\left[\delta_{\mathrm{RE} 01} /\left(1-\delta_{\mathrm{RE} 01}\right)\right]$ \\
\hline
\end{tabular}

(C) The authors. This is an open access article distributed under the terms of the Creative Commons BY-NC-ND Licence. 